\title{
Redes de projetos temporários: dinâmica das relações sociais
}

\section{Temporary networks projects: dynamics of social relations}

\author{
Ernesto Giglio' \\ Roseli Martins Silva ${ }^{2}$ \\ Wilson Bigas ${ }^{3}$
}

\section{Resumo}

O trabalho investiga a formação e dinâmica de redes temporárias, a partir dos princípios sociais de redes, e apresenta os dados de pesquisa do ramo de eventos móveis. A pesquisa bibliográfica revelou que são raros os trabalhos que investigam redes temporárias, isto é, grupos de empresas que se unem num trabalho coletivo, com tempo determinado. A proposição básica é que o prazo curto, como é o caso de eventos móveis, dificulta a rápida emergência de categorias sociais que formam as bases da rede, que são a confiança, o comprometimento, a governança e a solução de assimetrias. Foram realizadas entrevistas com representantes de empresas de eventos móveis. A análise sustentou a afirmativa em parte. A governança informal e a solução de assimetrias foram as categorias mais presentes, o que é coerente com as características técnicas e a necessidade de sincronismo do negócio. A rede dos entrevistados não apresenta sinais de confiança e comprometimento, mas uma parceria entre dois sujeitos apontou que essas categorias podem se desenvolver mesmo no curto período do evento. A presente pesquisa se justifica por trazer o benefício de se investigar as diferenças entre redes temporárias e redes perenes, quando o foco está nas relações sociais. Como benefício secundário, o artigo apresenta indicadores das categorias sociais, o que facilita a construção de instrumentos de coleta.

Palavras-chave: Teoria Social de Redes. Redes Temporárias. Eventos Móveis.

Professor e pesquisador do Programa de Pós-Graduação da Universidade Paulista - UNIP. E-mail: ernesto.giglio@gmail.com

2 Mestre em Administração pela Universidade Paulista- UNIP. Docente na Graduação e PósGraduação da Universidade Paulista. E-mail: roseli-martins@superig.com.br

3 Graduando em Administração pela Universidade Paulista- UNIP. E-mail: wilsonbigas@hotmail. com 


\section{Abstract}

The study investigates the formation and dynamics of temporary networks, from assumptions social networks that investigate temporary networks, groups of companies that come together in a collective work with a fixed deadline. The literature review revealed that rare are the studies that investigate temporary networks, ie groups of companies that come together in a collective work time-bound. The basic proposition is that the particular and short term, as is the case of mobile event, creates difficulties to the emergence of social categories that form the basis of networks, which are trust, commitment, governance and solutions of asymmetry. Interviews with representatives of companies moving events were held. The analysis support in terms the affirmative and informal governance and solutions of asymmetry were the most prevalent categories, which is consistent with the technical characteristics and the need for synchronization of the business. The network of respondents shows no signs of trust and commitment, but a partnership between two subjects pointed out that these categories can develop even in the short period of the event.

Keywords: Social Network Theory. Temporary Network. Mobile Events.

\section{Introdução}

As redes de negócios constituem um campo de estudo em ascensão, principalmente por causa da existência da base tecnológica de conexões, pela emergência de novos padrões sociais de comportamento (incluindo os de consumo) e pela nova situação de competição ocorrendo cada vez mais entre grupos, e não entre empresas isoladas (NOHRIA; ECLES, 1992).

O estudo de redes apresentou considerável incremento na década de 1990, tanto pela base tecnológica, que possibilitou conexões praticamente infinitas entre as organizações, quanto por certa exaustão dos modelos de explicação de competição isolada (NOHRIA; ECLES, 1992).

Os estudos têm sido alocados em três grandes perspectivas (GIGLIO; KWASNICKA, 2005): (a) racional e econômica, em que as redes são decisões estratégicas das empresas; (b) social e técnica, em que as relações sociais criam uma teia de fundo que orienta as ações; (c) a sociedade em rede, que afirma uma nova organização social. 
Ao se realizar um levantamento em bases nacionais e internacionais de artigos no tema redes que colocam as relações sociais como fundamento, advogam uma nova sociedade e investigam redes temporárias, as indicações dos bancos de dados, como Scielo e Proquest, foram zero, indicando o ineditismo do trabalho. Já as expressões isoladas, como trust (6.800), commitment (9.300) e network society (12.000) resultaram em muitas indicações. A expressão temporary networks resultou em 83 indicações, com vários trabalhos sobre informática, redes neurais, movimentos migratórios e Física. Encontrou-se uma referência em lacono, Esposito e Berni (2013) que utiliza a expressão Temporary Project Networks (TPNs), investigando a estrutura e a inovação em redes vinícolas na Itália. Encontraram-se outras referências, como Bertrand e Andreas (2013) e Villa (2002), que utilizam a expressão "redes temporárias", mas no seu conteúdo não tratam do tema.

Vale destacar que foi encontrado um capítulo de livro, de autoria de Jones e Lichtenstein (2007), que trata exatamente do tema. Nele, os autores buscam responder como os participantes se organizam diante da tarefa de um projeto temporário e comentam que, apesar de a temporalidade ser assunto que aparece nos textos sobre redes, ela é pouco investigada, não havendo modelos e teorias aplicáveis. Afirmam que investigar redes temporárias deve auxiliar a compreender as redes perenes - argumento defendido neste artigo. A proposta dos autores é sustentar um modelo que coloca o tempo e as relações sociais como determinantes dos modos de coordenação.

Dentro do campo de redes, as discussões se estendem por um leque que abrange o nascimento, os benefícios, a estrutura, as transações, o estudo de variáveis específicas e as bases de sua dinâmica. Neste último tópico, sobre as bases das redes, existem correntes racionais (redes são essencialmente movimentos estratégicos), econômicas (redes são soluções para problemas de custos), sociais (redes são estruturas de relações sociais que dirigem o comportamento) e da nova sociedade (redes de negócios são manifestações de uma nova sociedade organizada em redes). 
Este trabalho segue mais de perto as afirmativas das correntes sociais sobre o pano de fundo social, como base dos processos das redes, e as afirmativas da nova sociedade sobre o fato de todas as empresas estarem em redes, mesmo que não utilizem suas conexões. Com essa base, o texto discutiu a situação especial de redes temporárias - grupos de organizações que se unem para um objetivo, com tempo determinado e curto, como os eventos móveis. Nesse sentido, a questão que guiou a presente pesquisa foi: as relações sociais ainda se apresentam como bases de formação e manutenção das redes, ou outras variáveis estariam em jogo?

Para tanto, o objetivo geral consistiu em investigar a formação e dinâmica de redes temporárias, a partir das afirmativas da perspectiva social de redes (GRANOVETTER, 1985), principalmente o princípio da existência de um contexto social que dá sentido e orientação às ações técnicas e comerciais dos atores, e das afirmativas da sociedade em rede (CASTELLS, 1999), principalmente o princípio do desenvolvimento de uma nova sociedade baseada no formato em rede, o que inclui as formas de negócios.

No limite, o trabalho também investigou se esses agrupamentos exibiriam os sinais característicos de redes, que são a complexidade da tarefa, a interdependência, a necessidade de ação cooperada, a necessidade de troca de informações e a necessidade de comprometimento.

A análise bibliográfica prévia revelou que são raros os trabalhos que investigam redes temporárias, isto é, grupos de empresas que se unem num trabalho coletivo, com prazo determinado. As joint ventures podem ter prazos de execução relativamente longos, em anos, o que quase configura uma rede perene. O trabalho investiga as situações em que o prazo é curto, não passando de alguns meses, incluindo situações como planejamento e execução de eventos, feiras, shows, exposições e festivais. Conforme se afirma neste trabalho, os eventos móveis apresentam as características do formato em rede, já que estão presentes os sinais de interdependência, consciência de ação coletiva, 
necessidade de cooperação, fluxo de informações e presença de governança.

A proposição básica, derivada das afirmativas sobre o que mantém a perenidade de uma rede, é que o prazo determinado e curto dificulta a emergência de governança informal e laços sociais fortes de confiança e comprometimento, os quais auxiliam na longevidade das redes (GRANOVETTER, 1985; GULATI, 1995; GRANDORI; SODA, 1995). Nos itens seguintes, apresenta-se uma revisão bibliográfica sobre o tema, descrevem-se as afirmativas de apoio teórico e apresentam-se os dados da pesquisa realizada no negócio de eventos móveis.

\section{Referencial teórico}

$\mathrm{Na}$ presente pesquisa, utilizam-se os argumentos da sociedade em rede (CASTELLS, 1999), os argumentos das organizações em rede (NOHRIA; ECLES, 1992), o conceito de imersão (embeddedness) (GRANOVETTER, 1985) e a abordagem relacional das organizações (GRANDORI; SODA, 1995).

Segundo Castells (1999), está em desenvolvimento uma nova forma de sociedade, organizada no formato de redes. Os eventos que definem uma sociedade, como seus rituais, as rotinas de vida das pessoas e os modos de produção e consumo, estão se alterando no mundo, operando através da multiplicidade de ligações entre as pessoas (diferente do padrão de poucas pessoas) e pela simultaneidade (diferente das relações ao longo de um tempo).

Os negócios (os modos de produção e consumo) são manifestações da sociedade e também estão se transformando, operando no formato de redes. Significa, na trilha deste trabalho, que projetos temporários também se organizam em redes. A diferença, nesse caso, poderia ser a velocidade em que laços latentes, ou fracos, evoluem para laços fortes (no sentido de frequência e diversidade de conteúdos transacionados), voltando à sua característica de laço fraco após o evento. No intervalo não-evento, a rede está lá, mas as conexões estão latentes. A primeira 
afirmativa deste artigo é que, durante o tempo determinado (e curto) de um evento móvel, é possível verificar os sinais de redes, especialmente os indicadores de interdependência, das trocas, da solução de assimetrias e da governança.

De acordo com Nohria e Ecles (1992), é cada vez mais difícil entender os mercados e as organizações quando se realizam análises de empresas isoladas. Afirmam os autores que a análise na perspectiva de redes é coerente com os formatos atuais de negócios e trazem vantagens para a compreensão de certos temas, como poder e liderança, já que elas aparecem nas conexões, as quais são visíveis e possíveis de serem investigadas. O princípio que mais interessa ao presente trabalho é a afirmativa de que todas as empresas estão em redes, e a rede é o conjunto de conexões das organizações que participam do negócio. Em outros campos da Administração, esse conjunto é denominado de ambiente organizacional.

Se todas as organizações estão em redes, o que determina as diferenças entre redes? Novamente, utiliza-se a noção de laço fraco e forte, conforme definido por Granovetter (1985). Para o autor, as pessoas estão imersas em seus relacionamentos nas redes, significando o quanto elas interagem com outras pessoas, o quando despendem esforços para os trabalhos coletivos do grupo em que participam e qual a sua posição na estrutura dos laços na rede. Em outras palavras, o quanto cada pessoa está comprometida na rede, obtendo seus benefícios e perdendo parte de sua liberdade. Existem duas situações-limite: na primeira, o sujeito está muito imerso na rede, vive para a rede, tem posição importante no grupo, realiza frequentes trocas de informações de toda natureza (comercial, técnica, social, política), obtém vantagens que solitariamente não conseguiria e está, de certa maneira, preso pelas regras e compromissos do grupo - seu laço é forte; na segunda situação, o sujeito pouco participa da rede, tem objetivos e expectativas secundárias na sua lista de prioridades, não tem posição e papel importante, goza de certa liberdade para estar em outras conexões e obtém poucas vantagens dos resultados da rede - seu laço é fraco. 
As diferenças entre redes, portanto, encontram-se justamente na dominância ou não de laços fortes e fracos, o que caracteriza redes mais fechadas e organizadas em processos e estruturas (uma cadeia automotiva, por exemplo) ou redes mais abertas e incipientes em estruturas e processos (uma rede de lojistas de bairro, por exemplo, para resolver problemas comuns como segurança). Aplicando o princípio da sociedade em rede, afirma-se que sempre haverá algum grau de ligação, mesmo que bem fraco. Significa, na trilha deste trabalho, que projetos temporários seriam exemplos de redes com laços fracos que rapidamente evoluem para fortes num tempo determinado e depois evoluem novamente para fracos, até a proximidade de um novo evento. Essa sazonalidade das redes não seria encontrada nas formas mais perenes. A segunda afirmativa do artigo é a de que há um movimento rápido de evolução de laços fracos para fortes durante o tempo de um evento, vindo depois uma fase de acomodação e o retorno ao status de laço fraco.

O último argumento, o da abordagem relacional, afirma que o objeto de investigação nas redes é a relação entre os atores, em vez da estrutura das posições, dos processos e controles ou dos resultados. Essa perspectiva mais social, com representantes como Granovetter (1985), Grandori e Soda (1995) e Powell (1987), afirma que o coração das redes está nas relações sociais entre os atores, sejam relações de aproximação, como a cooperação e a confiança, sejam relações de distanciamento, como jogos de poder e competição interna. Utilizando princípios da Sociologia, principalmente das afirmativas sobre pequenos grupos, a abordagem social de redes afirma que as relações sociais constituem a teia de fundo que dá sentido e orientação às decisões de negócios. Dito de outra maneira, as pesquisas que seguem essa linha de raciocínio investigam a presença e o conteúdo das relações sociais, as quais explicariam a forma e dinâmica de uma rede específica. $\mathrm{Na}$ trilha do presente artigo, afirma-se que o tempo curto e a pressão de ação do evento móvel obrigam os participantes a criar laços sociais de controle do comportamento, com circuito restrito de informações, difusão de macrocultura do negócio e centralidade por autoridade. Essas 
categorias foram selecionadas a partir do trabalho de Jones, Hesterly e Borgatti (1997).

A leitura das afirmativas indica que o evento móvel não descaracteriza as redes; apenas traz para o primeiro plano certos fatores, como desenvolvimento da força dos laços, os quais, em redes perenes, localizam-se em um contexto. Assim, o objetivo da pesquisa sobre eventos móveis é encontrar esses fatores salientes e, se possível, construir um modelo explicativo das redes temporárias.

Partindo da afirmativa da análise relacional, utilizando afirmativas da literatura clássica e apoiado em modelo desenvolvido pelos autores (referência omitida), coloca-se que quatro categorias sociais seriam as mais salientes ou explicativas das redes temporárias: (a) confiança, definida como a situação de um ator colocar-se na dependência de outro (HERNANDEZ; MAZZON, 2005; BEUGELSDIJK, 2006; BOEHE; BALESTRO, 2006; GIGLIO; RIMOLI; SILVA, 2008; (b) comprometimento, definido como a situação de alguém colocar a ajuda e participação no grupo acima dos interesses individuais (LORANGE; ROOS, 1991; LARSON, 1992; MAYNTZ, 1993); (c) governança, que são os mecanismos de ordenação e controle dos processos e do comportamento (GRANDORI; SODA, 1995; JONES; HESTERLY; BORGATTI, 1997); e (d) a solução de assimetrias, que é a solução das diferenças que causam atritos, problemas ou jogos de poder no grupo (GRIFFITH; PIGGOTT, 1994). Do resultado da presença e do conteúdo manifesto dessas quatro categorias, desenham-se a forma e a dinâmica da rede. A expressão gráfica desse conjunto de argumentos pode ser vista na Figura 1. A unidade estrutural de análise é a tríade, a relação entre três atores. 
Figura 1: O desenho de pesquisa, com as relações entre três atores como unidade de estudo das categorias sociais presentes em eventos móveis.

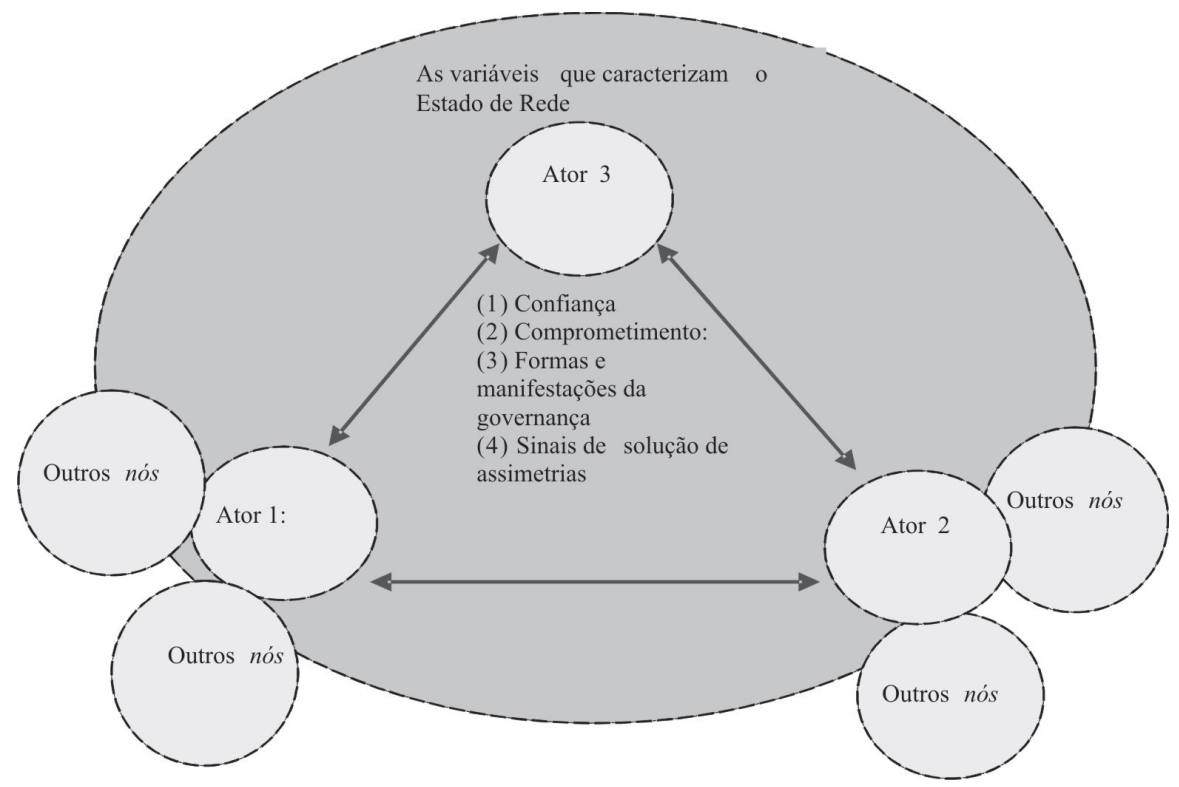

Fonte: Elaborada pelos autores (2014)

A partir desses princípios, buscou-se raciocinar sobre as redes temporárias. Redes temporárias se caracterizam por um objetivo coletivo que se alcança num prazo determinado, findo o qual as partes não precisam continuar suas rotinas de ações coletivas. Durante o tempo do evento, existiriam sinais de variação significativa das quatro categorias ou o fato de o tempo ser curto e determinado modifica prioridades e outras variáveis se tornam mais importantes?

\section{Metodologia}

Tratando-se de variáveis qualitativas, que não se reduzem a dimensões métricas, a pesquisa se caracteriza por ser qualitativa 
(VERGARA, 2009), do tipo exploratória (CERVO; BERVIAN; DA SILVA, 2007).

O negócio escolhido para caracterizar uma rede temporária foi o de eventos móveis, que são shows como a festa de Primeiro de Maio; encontros como eventos corporativos, treinamentos e celebrações de empresas; festividades como formaturas, casamentos, aniversários, que são organizados especificamente para aquele evento, montando-se e desmontando-se toda a infraestrutura necessária.

A primeira etapa consistiu em definir operacionalmente as quatro variáveis qualitativas, o que não foi tarefa simples, já que são raros os esforços nesse sentido na literatura brasileira. Conforme já se apresentou no item de discussão teórica, o caminho conceitual é de expressar as situações de relacionamento entre atores. Os indicadores apresentados no Quadro 1 foram construídos a partir de três eventos: (a) os indicadores estavam presentes nos artigos da revisão bibliográfica; (b) testes anteriores (referências omitidas para não revelar os autores) mostraram a validade de alguns indicadores; e (c) construção direta dos autores a partir da ideia central contida na definição operacional.

Quadro 1: O conjunto de fatores, com seus indicadores, que caracterizam o estado de organização de uma rede.

\begin{tabular}{|c|c|c|c|}
\hline Variável & Conceito dominante & $\begin{array}{l}\text { Conteúdo a ser } \\
\text { observado }\end{array}$ & Alguns indicadores \\
\hline $\begin{array}{c}(1) \\
\text { Confiança }\end{array}$ & $\begin{array}{l}\text { Colocar-se na } \\
\text { dependência do outro. }\end{array}$ & $\begin{array}{l}\text { Atitudes e ações nas } \\
\text { quais o sujeito se expõe } \\
\text { ao coletivo ou fica na } \\
\text { dependência do outro, sem } \\
\text { recorrer a mecanismos } \\
\text { formais de controle. }\end{array}$ & $\begin{array}{l}\text { 1.1. Expor suas fraquezas e dependências } \\
\text { aos outros. } \\
\text { 1.2. Assumir uma responsabilidade cuja } \\
\text { execução depende de outro, confiando que } \\
\text { esse outro irá realizar. } \\
\text { 1,3. Dispor seus recursos, de qualquer } \\
\text { natureza, para serem usados por outros, } \\
\text { sem necessidade de salvaguardas. } \\
\text { 1.4. Comportamentos e atitudes que } \\
\text { mostram que o ator acredita que os outros } \\
\text { seguem as regras. }\end{array}$ \\
\hline $\begin{array}{c}\text { (2) } \\
\text { Comprometimento }\end{array}$ & $\begin{array}{lr}\text { Colocar-se } & \text { à } \\
\text { disposição } & \text { para } \\
\text { ações } & \text { coletivas; } \\
\text { não tirar proveito da } \\
\text { dependência r dos } \\
\text { outros. }\end{array}$ & $\begin{array}{l}\text { Atitudes e ações para } \\
\text { atingir objetivos coletivos } \\
\text { ou ajudar outro ator, } \\
\text { mesmo sem benefício } \\
\text { pessoal imediato. }\end{array}$ & $\begin{array}{l}\text { 2.1. Participar regularmente de reuniões e } \\
\text { decisões. } \\
\text { 2.2. Ajudar a outro, mesmo sem benefício } \\
\text { próprio. } \\
\text { 2.3. Assumir responsabilidades de ações } \\
\text { conjuntas. } \\
2.4 \text {. Comportamentos que evidenciam } \\
\text { a disposição para continuidade dos } \\
\text { relacionamentos. }\end{array}$ \\
\hline
\end{tabular}




\begin{tabular}{|c|c|c|c|}
\hline $\begin{array}{l}\text { (3) } \\
\text { Sinais de solução } \\
\text { de Assimetrias }\end{array}$ & $\begin{array}{l}\text { As diferenças de } \\
\text { capacidades } \\
\text { recursos precisam ser } \\
\text { resolvidas }\end{array}$ & $\begin{array}{l}\text { Diferenças de qualquer } \\
\text { natureza que sejam } \\
\text { relevantes na organização } \\
\text { da rede e que precisam ser } \\
\text { resolvidas. }\end{array}$ & $\begin{array}{l}\text { 3.1. Diferenças de qualquer natureza entre } \\
\text { os atores. } \\
\text { 3.2. Conflitos originados pelas assimetrias } \\
\text { 3.3. Ações para solução dos conflitos. }\end{array}$ \\
\hline $\begin{array}{l}\text { (4) } \\
\text { Formas e } \\
\text { manifestações de } \\
\text { governança }\end{array}$ & $\begin{array}{l}\text { Regras de incentivo } \\
\text { para participar do } \\
\text { grupo e controle do } \\
\text { comportamento. } \\
\text { Pode ser formal ou } \\
\text { informal. }\end{array}$ & $\begin{array}{l}\text { Toda e qualquer regra, } \\
\text { explícita ou implícita, que } \\
\text { coloque restrições ao } \\
\text { comportamento, incentive } \\
\text { as ações coletivas e } \\
\text { proteja os recursos, sejam } \\
\text { coletivos ou individuais. }\end{array}$ & $\begin{array}{l}\text { 4.1. Regras sobre admissão e exclusão de } \\
\text { atores do grupo. } \\
\text { 4.2. Regras sobre penalidades. } \\
\text { 4.3. Controle por autoridade, ou reputação } \\
\text { (de um ator mais poderoso, por exemplo). } \\
\text { 4.4. Controles sociais (por exemplo, } \\
\text { existência de blogs, sites comunitários } \\
\text { e outros, com informações sobre os } \\
\text { participantes). }\end{array}$ \\
\hline
\end{tabular}

Fonte: Elaborada pelos autores (2014)

Os indicadores apresentados são sugestões que não pretendem esgotar a lista, e sim mostrar a linha geral de questionamento e esclarecer o conteúdo do roteiro utilizado. O quadro, por si, é uma contribuição metodológica importante, uma vez que não se encontraram similares na literatura brasileira.

A partir dos indicadores, foi desenvolvido o roteiro de entrevista. Tratando-se de uma entrevista não estruturada, colocou-se uma pergunta de abertura, solicitando ao sujeito que discorresse sobre as características do negócio, principalmente sobre se existe a necessidade de ações coletivas ou se é uma sequência de ações individuais.

\section{Resultados e análises}

O negócio de eventos (fixos ou móveis) movimenta muitas empresas fabricantes de equipamentos, como produtos de som e imagem, sendo a maioria de empresas internacionais, com alguma participação de fabricantes nacionais. Os fabricantes vendem seus equipamentos para empresas que são as fornecedoras dos produtos para os eventos, algumas tendo toda a linha de infraestrutura, outras mais especialistas. Esses fornecedores se relacionam com os agentes, que são os que organizam todo o evento para o cliente. A relação entre os agentes e os fornecedores é intensa quando há um projeto de evento. Os clientes são variados porque existem eventos com bilheteria, como shows, eventos corporativos, políticos e sociais. 
Tudo é muito variado nesse negócio, pois existem eventos pequenos, praticamente sem agentes, com pequenos fornecedores e equipamento pouco sofisticado, até megaeventos, como o carnaval do Rio de Janeiro, com grandes fabricantes, fornecedores e agências. As análises econômicas de especialistas, como das revistas Exame e Valor, afirmam que é um mercado que cresce algo em torno de $7 \%$ ao ano, com dominância dos eventos considerados de pequeno porte, até duas mil pessoas e com movimento estimado de 16 bilhões de reais no estado de São Paulo, considerando 2013/2014.

Com essa segmentação e com o mercado de eventos sofrendo variações e sazonalidades, o negócio é altamente competitivo, com ciclos curtos de vida de produtos de tecnologia e com interesses de comissões que jogam um importante papel na escolha de empresas participantes. Embora existam sinais claros de interdependência (todas as partes devem estar integradas no evento), complexidade (pela tecnologia e sincronismo envolvido), necessidade de cooperação e troca de informações, e pressões para o comprometimento - categorias que indicam a presença de redes. Os relatos informais prévios de técnicos desenharam uma situação que pouco caracteriza o formato de redes.

Nos itens seguintes, apresentam-se os dados relevantes colhidos nas entrevistas. Foram realizadas quatro entrevistas com os sujeitos selecionados, utilizando-se a técnica da bola de neve, chegando a um ponto de exaustão.

\section{Sujeito 1 - Fabricante e prestador de serviços de sistemas elétricos}

O sujeito 1 é conhecido no negócio de sistemas elétricos para eventos em função do longo tempo de atuação. Durante alguns anos, era o único que fabricava equipamentos de proteção e conhecia os atalhos de adaptação de equipamentos internacionais para as condições brasileiras.

Seu concorrente mais próximo é o sujeito 2. Afirma que os outros são técnicos sem estrutura que acabam prestando serviço para pequenos 
eventos. Essa raridade de pessoas habilitadas deixa a empresa do sujeito numa situação confortável no mercado. A existência desse serviço se deve às diferenças de tomadas e voltagens no Brasil, obrigando a arranjos locais para adaptação dos equipamentos internacionais. Isso exige constante troca de informações no planejamento e execução de cada evento. Por outro lado, essa diversidade de características locais dificulta a formação de um grupo constante. Para cada projeto, existem pessoas envolvidas.

O mercado é caracterizado por um crescimento considerado bom pelo sujeito, embora sejam pequenas empresas que estão entrando, enquanto as grandes mantêm um ritmo de crescimento normal (o mesmo ritmo da empresa do sujeito, que atende basicamente a esses grandes). Com o Brasil entrou em circuitos mundiais (de shows, por exemplo), o mercado vem crescendo. O governo e o público em geral não têm consciência sobre os perigos elétricos envolvidos nos eventos, e há ausência de fiscalização. A vistoria realizada pelos bombeiros para liberar um evento fica centrada nas questões de segurança, como escadas, extintores e saídas, mas não na parte elétrica.

Sobre a questão da pesquisa, o negócio apresenta poucos sinais de organização em rede, sendo mais evidentes os casos de compartilhamento de informações quando técnicos estrangeiros necessitam conhecer as especificidades do sistema elétrico brasileiro, o que significa a solução de assimetrias. O sujeito atende às empresas de evento, as quais mantêm uma competição acirrada entre si, mas há um pequeno número de empresas fiéis que seguem suas orientações (é comum as empresas não seguirem normas técnicas de segurança, pois não há fiscalização), o que indica governança informal por reputação. Para esses mais fieis, o sujeito fica à disposição para ajudar a solucionar qualquer problema antes e durante o evento.

É, portanto, uma configuração muito inicial de redes, com pequenos exemplos de compartilhamento, comprometimento e confiança, com domínio dos sinais de solução de assimetrias e de governança informal, com o sujeito sendo ator central como referência técnica. Do lado dos 
fabricantes, há uma grande variedade de indústrias de cabos, aparelhos de som, aparelhos de vídeo, entre outros com relações mais comerciais. Essas empresas não têm interesse em trabalho conjunto (como acompanhar os eventos para ver o funcionamento dos seus aparelhos) e desconsideram a importância econômica do negócio no Brasil.

Sobre as categorias selecionadas, pode-se comentar:

Comprometimento - São raros os exemplos e, nesses casos, predomina mais a aproximação entre o fornecedor e o agente. Recebido o material do sujeito, as empresas de eventos trabalham por si, nem sempre seguindo as normas técnicas ou as orientações dadas pela empresa do sujeito. Há, no entanto, um grupo mais seleto de empresas de eventos que é mais fiel ao sujeito e segue as normas técnicas. Podese afirmar que seria um embrião de uma rede de cooperação técnica.

Confiança - Na mesma linha do comprometimento, o sujeito tem um diminuto circuito de empresas em que confia serem técnicas e éticas e nas quais ele sabe que seus ensinamentos e treinamentos serão acatados e utilizados. Trata-se de confiança no sentido de ações futuras.

Governança - Pelo formato das relações de negócios e pelo tempo de execução dos projetos, não foram detectados sinais claros de governança formal para trabalho coletivo. Como o sujeito é referência técnica, há indícios de governança informal, por reputação.

Assimetrias - As empresas participantes constituem um leque bem diversificado sobre recursos técnicos, informações, tamanho da empresa e especializações, atendendo desde megaeventos, como o carnaval, até eventos menores, como casamentos. Não há associação, sindicato, grupos de empresários ou qualquer movimento coletivo institucionalizado. Cada evento fica a cargo de algum especialista, o qual realiza as trocas para diminuir as assimetrias (nesse caso, assimetrias de conhecimentos).

A conclusão é que o negócio de prestação de serviços de sistemas elétricos associados aos eventos móveis se caracteriza por um formato 
incipiente de redes, com raros sinais de relações sociais que sustentem as ações de negócios. O sujeito é ator importante nessa rede pelo seu conhecimento técnico, tendo algum poder de governança informal, mas não tem o poder de unificação ou padronização de serviços que pudesse iniciar um movimento de ação coletiva (um grupo de trabalho mais constante). Essas redes temporárias, portanto, são incipientes, mesmo considerando o fato de algumas organizações se encontrarem regularmente nos eventos.

\section{Sujeito 2 - Fabricante de equipamentos elétricos de segurança}

Tal como o sujeito 1, este sujeito também fabrica equipamentos de segurança elétrica para eventos. A linha geral do seu discurso indica que a resposta ao problema de pesquisa é que se trata de um negócio com formato incipiente de rede, com ilhas de cooperação e interdependência. Em termos dos princípios da sociedade em rede, pode-se afirmar que não existem consciência e prática de trabalho coletivo no negócio.

Há convergência com o discurso do sujeito 1 sobre características do negócio, com adaptações nem sempre técnicas e ausência de fiscalização. O relatório de uma norma técnica é assinado por um engenheiro que não acompanha o evento. Essa norma é entregue à prefeitura e aos bombeiros que autorizam o evento, raramente fiscalizando no momento de sua produção.

Ao contrário da afirmativa do sujeito 1, informa que o negócio de eventos está em declínio, enquanto sua empresa está crescendo. No mercado de artistas brasileiros, há uma concentração de renda (artistas famosos que agenciam artistas emergentes) e de empresas (lobby para certos produtos e empresas). O mercado não tem um desenho claro de ações coletivas, apresentando ilhas de cooperação. O negócio tem movimentos que o transformam, como os artistas tornando-se agenciadores, com lojas de produtos fechando, aglutinação nas mãos de grandes e usuários médios sendo os grandes compradores. Os produtos têm curto ciclo de vida, pela evolução tecnológica, com acirrada 
competição entre os fabricantes. O sujeito participa dessa competição, incluindo movimentos de ataque ao sujeito 1. São raros os exemplos de cooperação e trocas, mas, conforme se verá no relato do sujeito 3 , há uma parceria entre os dois.

Afirma que, pela dinâmica do mercado, não é possível a empresa se fixar em clientes mais fiéis, pois são poucos e a frequência de ações conjuntas (eventos repetitivos) é baixa. O sujeito precisa buscar sempre outros clientes não fiéis.

Sobre confiança, afirma o sujeito que construiu uma imagem de confiança técnica e pessoal junto aos usuários, resultado de seu acompanhamento de perto nos eventos (o que é raro entre os fabricantes). Sobre o comprometimento, os sinais são de ausência. As regras são de competição e de aglutinação nas mãos de alguns. O sujeito tem algumas ações isoladas de troca de informações, mas a regra geral no negócio é proteger as informações. Sobre conflitos de assimetrias, eles existem e não há casos descritos de solução conjunta. Quando o sujeito está numa posição mais forte, ele dita as regras técnicas; quando está numa posição mais fraca, o cliente dita as exigências de produtos e negociações.

Excetuando-se algumas informações contraditórias entre os dois sujeitos (como o crescimento do mercado), os dados são convergentes em mostrar um negócio pouco desenvolvido no formato de redes, com raros exemplos de trabalhos conjuntos, com forte competição vertical e horizontal, e ausência de fiscalização, facilitando as ações competitivas. Considerando o suposto de sempre existirem redes, nesse negócio, estaria num nível bem incipiente de consciência, ação, cooperação e comprometimento. Por outro lado, agora comentando a divergência, o discurso do sujeito 2 é mais influenciado por um pensamento de competição isolada do que o sujeito 1. Este acredita na possibilidade de união e trabalho em grupo, enquanto aquele acredita que o negócio só funciona na base da competição. 


\section{Sujeito 3 - Empresário fornecedor de equipamentos}

"Eu fui criado sem a necessidade de passar por cima de ninguém para conseguir as coisas [...]. Se a pessoa me respeita, eu respondo da mesma forma."

"Esse ambiente de show business é muito sujo. Alguém, para te passar a perna, não custa nada."

"Eu compro produtos do sujeito 2 porque ele desenvolveu produtos que resolvem meus problemas e que, no meu começo, ele me mandou equipamentos simplesmente na confiança e de olhar lá na frente como um possível cliente."

O sujeito 3 é o fornecedor intermediário que compra equipamentos dos fabricantes (sujeitos 1 e 2) e instala no evento a partir do contrato com os agentes. Diferente dos sujeitos anteriores, seu discurso foi mais voltado para os aspectos sociais das relações entre partes. As frases selecionadas indicam a característica de competição e oportunismo do negócio e a atitude do sujeito em agir de forma ética e transparente, enquanto houver contrapartida. Sua rede de relacionamento, portanto, é fundada na reciprocidade. Tal como o discurso do sujeito 2, também descreve o negócio com poucas ações coletivas, com ilhas de cooperação e interdependência, em que ele se considera exceção.

Diferentemente dos sujeitos anteriores, ele valorizou a relação social, a ética e a lei do olho por olho. Por princípio, está disposto a ajudar e confia em ser ajudado, mas qualquer desvio de rota o transforma numa pessoa comercial normal, isto é, competitiva. Sua relação com o sujeito 2 é de parceria, já que cada um acreditou no relacionamento de longo prazo com o outro e investiu recursos, tempo e dinheiro. Agora, é uma parceria bem estabelecida, mesmo reconhecendo que seu parceiro, o sujeito 2 , é extremamente competitivo.

O sujeito retrata um mercado com demanda em expansão, e seu lugar nesse ambiente agora é mais destacado, após oito anos de atuação. Conta que o mercado é sazonal, com baixa procura no meio 
do ano, o que acirra a competição. Além disso, existem comportamentos oportunistas e calotes de pagamentos.

Conforme os princípios de teoria de redes, o comportamento oportunista e a competição acirrada dificultam a emergência de ações coletivas e de relações sociais de aproximação. Ao contrário do que afirmam Castells (1999) e outros autores, sobre o fato de a tecnologia permitir a emergência de redes, afirma o sujeito que, antigamente, o circuito era mais fechado, havendo mais parceria, confiança e comprometimento. Com a tecnologia, facilidade de acesso e piora da economia brasileira, isso desapareceu.

O sujeito é fornecedor de produtos de som e luz para eventos, adquirindo-os dos fabricantes (principalmente do sujeito 2) e realizando as demandas das agências, que atendem o cliente final. Elas, portanto, precisam confiar no trabalho, cuja contrapartida é o comprometimento de realizar o que foi acordado. Afirma o sujeito que a união das relações sociais e técnicas são um padrão entre eles e as agências. Eventualmente, ocorre um problema de autoridade ou até de empatia. O autor diz que há muito ego no negócio, no sentido de agenciador e clientes finais forçarem suas vontades.

Sobre sua parceria com o sujeito 2 , a história remonta ao início de sua empresa, há oito anos. $\mathrm{O}$ sujeito 2 o ajudou porque viu seu potencial como futuro parceiro. Muitos, no entanto, não o ajudaram e hoje pedem sua ajuda (no que são negados, na sua filosofia de olho por olho). A empresa compete com várias outras, mas o sujeito construiu uma rede comercial com aproximadamente 10 agências mais fiéis e um circuito de concorrentes que se ajudam, formando uma rede mais calcada na confiança e reciprocidade. O tempo tem um papel importante nessa história, já que esse grupo com laços mais fortes repete suas ações de negócios.

Sobre confiança, afirma que seu primeiro princípio é confiar nas pessoas até que se prove o contrário. Relata algumas situações em que agiu de forma muito transparente, realimentando o circuito de confiança mútua. O discurso mostra também a presença da confiança 
conforme os resultados obtidos e também por reconhecimento técnico. Sobre comprometimento, os sinais foram mais fracos, tanto no sentido de felicidade quanto no de cumprir o prometido. As regras são de competição e de aglutinação nas mãos de alguns. Sobre assimetrias, relata que existem conflitos e que seu conhecimento técnico dá vantagem na solução das exigências de autoridades. A conversa fica mais difícil quando do outro lado há um ego inflado (um artista exigente, por exemplo).

A relação com o sujeito 2 , especificamente, caracteriza uma parceria, com a presença de interdependência. O sujeito 2 envia produtos para o sujeito 3 testar, adquirindo o direito de uso antes dos outros. São benefícios mútuos. O discurso do sujeito valorizou bastante as ações, estratégias e formas de relacionamento do sujeito 2 , sendo muito grato a este pela oportunidade no início de sua carreira, o que influencia na prevalência de comportamento comprometido. Na outra ponta, na relação com os agentes, cita o caso do sujeito 4 como alguém com quem mantém relações de confiança e comprometimento mútuo (o sujeito 4 permite, por exemplo, que o sujeito tenha contato direto com o cliente, o que é muito raro no ambiente de negócios).

O discurso, portanto, segue de perto as afirmativas de Gulati (1995) sobre a construção da confiança em eventos repetitivos. O sujeito tem um círculo de fabricantes e agentes que confiam nele, constituindo uma rede fundada na confiança e no comprometimento.

Considerando os discursos até o momento, os dados são convergentes em mostrar um negócio que tem fracas características do formato em rede, com raros exemplos de trabalhos conjuntos e com forte competição. O sujeito, no entanto, ofereceu dados sobre uma rede em desenvolvimento, na qual ele é um ator central, que une agentes (como o sujeito 4), fornecedores (como ele), fabricantes (como o sujeito 2) e concorrentes. A existência de relações mais fortes entre um grupo no qual o sujeito participa parece estar associada a dois elementos básicos: (a) a presença de transparência no relacionamento; (b) a possibilidade de realizar mais trabalhos conjuntos no tempo. Essa segunda interpretação 
vai de encontro às afirmativas de autores clássicos sobre estágios da rede e tempo de maturação, até se atingir um equilíbrio de forças, um equilíbrio de governança formal e informal e um conhecimento sobre como resolver e utilizar as diferenças causas pelas assimetrias (LARSON, 1992).

Em outras palavras, as redes temporárias carecem de um tempo de maturação, que é a construção gradativa das bases sociais, configurando-se como redes pouco equilibradas, com sinais fortes da presença de competição interna, jogo de poder e oportunismos. Essa conclusão é contrária à afirmativa da existência de redes e à afirmativa sobre a rápida evolução das relações sociais.

\section{Sujeito 4 - Agente de eventos}

"O contrato só tem direitos para o cliente, e o agente só tem obrigações."

"Qualquer tipo de evento que envolve muita gente, você tem muita responsabilidade e todo mundo precisa de todo mundo, independente do segmento... porque se um faz alguma coisa errada [...], todo mundo fica envolvido."

A entrevista mostrou, de maneira mais clara que as anteriores, a característica geral do negócio e a possibilidade de emergência de redes temporárias. Ocorre que o negócio de eventos móveis apresenta competição acirrada nos três pontos da produção (agentes, fornecedores e fabricantes).

Cada evento tem um prazo específico e características também especiais (de local, luz, som, tipo de palco etc.), determinando que se forme um grupo de trabalho par aquele projeto, o qual se desfaz ao final do evento. Esse grupo temporário precisa agir com cooperação e comprometimento, pois as ações se integram para que o evento ocorra. Elas formam, dessa maneira, uma rede temporária com função de cooperação e sincronismo. Findo o evento, a rede se desfaz e algumas organizações voltam a se encontrar no próximo evento. Conforme 
relato do sujeito, a temporalidade desses grupamentos é um fator que desestimula a emergência de ações coletivas de comprometimento, no sentido de ações para a continuidade das relações. Como os eventos são espaçados (alguns são anuais), mesmo que algumas organizações sejam as mesmas do último encontro, é necessário reconstruir as bases de cooperação e comprometimento a cada vez.

O sujeito 4 é um produtor independente, que trabalha há muitos anos no ramo, passou por vários empresas de eventos e hoje desfruta da imagem de competência e relacionamento positivo junto à cadeia de clientes e fornecedores. O sujeito 3 relatou que sua relação profissional com o sujeito 4 tem um forte componente de relação afetiva e empática, o que the possibilita a direção de alguns eventos regulares em São Paulo. Seu discurso indicou que o agente ocupa um lugar central no conjunto de organizações do evento, mas isso não significa posse e uso do poder. As relações com os clientes normalmente são negociadas (a cada demanda) e as relações com os fornecedores têm um forte componente técnico, além de confiança. Suas falas selecionadas ao início desta descrição mostrar esse caráter de dificuldade do ator que é intermediário, sem necessariamente ter poder.

Sobre confiança, afirma o sujeito que ela existe nos seus relacionamentos, mas não é possível confiar cegamente no outro. A cada projeto, é necessário conversar e reafirmar o compromisso e a qualidade técnica. As experiências anteriores servem de apoio para voltar a procurar o outro, mas não para fechar acordo no escuro. Sobre comprometimento, o discurso se voltou para o momento do evento, afirmando que é necessária a presença de todos os fornecedores, caso surja algum imprevisto. Ele relata casos positivos e negativos sobre essa presença a solução de problemas.

Sobre conflitos de assimetrias, eles existem e as negociações são muito delicadas e especiais. Cada caso, cada evento, cada cliente e cada momento do mesmo cliente e do mesmo evento suscitam formas distintas de relacionamento, autoridade, imposição e improvisação. Embora com fornecedores a linguagem e o trato sejam um pouco mais 
técnicos, também há uma dinâmica constante, no sentido de assegurarse da qualidade e assistência do fornecedor. Sobre governança, comenta que não existem regras fixas, não há um padrão de ação, porque cada projeto é diferente do outro. Pode existir um padrão de gestão, mas não há um padrão de ações nos projetos. Ainda sobre governança, o sujeito indicou que exerce um controle técnico via relação social, isto é, visitando, conversando, tomando café e indagando sobre questões técnicas.

Os discursos dos sujeitos foram convergentes em afirmar a competição do negócio, mas divergentes quanto às possibilidades, exemplos e existência de sinais de redes. O sujeito 4 , na sua posição de ator central, mas não poderoso, precisa e depende de outros para que tudo dê certo, estabelecendo vínculos de compromisso, reciprocidade e controles - vínculos os quais os sujeitos anteriores, que estão na linha de fornecedores, não afirmam existir ou dizem ser raros. Para estes sujeitos, os vínculos são essencialmente comerciais, sem fidelidade e reciprocidade exagerada. Em outras palavras, os sujeitos 2 e 3 afirmam com mais ênfase o caráter de mercado do negócio, havendo parcerias com retorno planejado.

Entre o sujeito 3 e o sujeito 4, há uma parceria mais desenvolvida pelas relações sociais, embora o sujeito 4 deixe claro que não se fecha nenhum acordo no escuro. Explica o sujeito que as partes precisam estar muito envolvidas e comprometidas, afirmando que entre ele e o sujeito 3 existe um compromisso. Entre o sujeito 3 e o sujeito 2, existe uma parceria de negócios, cada qual ajudando o outro, com benefícios mútuos. Os agentes, como o sujeito 4 , relacionam-se com os fornecedores de produtos (como o sujeito 3), mas não precisam conhecer e se relacionar com os fabricantes (como os sujeitos 2 e 1), indicando que quando existem sinais de rede, eles se restringem à díade.

\section{Análise dos dados}

As quatro entrevistas foram convergentes o suficiente para se encerrar a coleta e escrever os comentários. Das quatro categorias 
selecionadas, a governança mostrou ser a mais saliente, a mais evidente, principalmente pela necessidade de customização de produtos e serviços para cada evento. O agente (sujeito 4) usa boa parte de seu tempo de gestão do projeto para controlar informalmente as pessoas, os produtos e os processos. Um dos motivos é que ele é a ponte entre os fornecedores e o cliente, portanto, qualquer falha será creditada a ele. A segunda categoria mais evidente, cuja função é complementar à governança, é o comprometimento, principalmente no seu indicador 2.3 (assumir responsabilidades de ações conjuntas). A terceira categoria em evidência foi a solução de assimetrias. Os aspectos técnicos envolvidos e suas especificidades obrigam as partes a trocar informações e buscar simetrias de ações. A confiança foi a categoria menos evidente, e quando apareceu, foi no sentido de esperar que o outro cumprisse o que devia, o que é um indicador secundário. O principal indicador da confiança, que é colocar-se na dependência do outro, surgiu apenas em um breve relato do sujeito 4 , quando ele permite que o sujeito 3 fale diretamente com o cliente, mesmo com os riscos de perder sua autoridade e posição.

O resumo desses conteúdos pode ser visto na Figura 2.

Figura 2. Os conteúdos de quatro categorias presentes em entrevistas de atores de redes de eventos móveis.

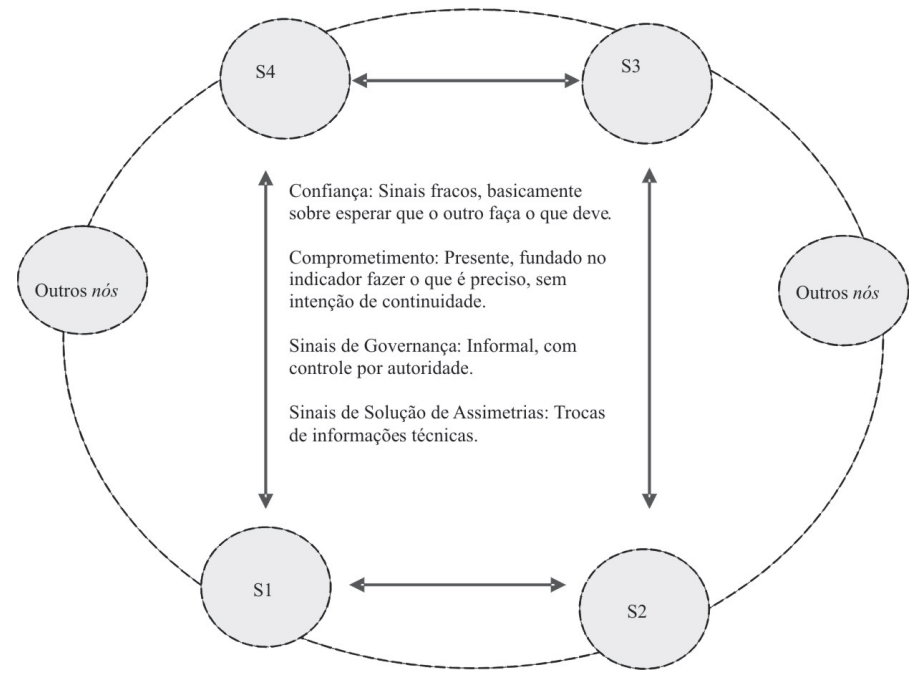

Fonte: Construção dos autores, 2014 
A afirmativa da presença de uma rede, mesmo com sinais fracos, foi sustentada. Os dados mostram a presença de interdependência, complexidade de tarefas, necessidade de trocas, e que o resultado só é possível na ação coletiva. São sinais do formato em rede.

Já a afirmativa da presença de laços sociais fortes não foi sustentada. As duas categorias de relações de aproximação (confiança e comprometimento) estão fracamente presentes, e sua natureza é mais voltada para as obrigações. A afirmativa sobre a pressão do tempo em criar laços de controle foi sustentada, já que a governança informal foi a categoria mais presente. A solução de assimetrias aparece, mas não tem o caráter de formação de grupo, e sim para cumprir obrigações e diminuir os riscos de acidentes.

As quatro entrevistas não ofereceram evidências do efeito sanfona da rede, ou seja, de um movimento de crescimento dos laços fortes durante o evento e acomodação após o mesmo.

No entanto, voltando o olhar para evidências secundárias, percebe-se que as relações entre o sujeito 3 e 4 são pautadas também por relações de confiança e por comprometimento, no sentido de continuidade da relação. Essas duas pessoas trabalham juntas há pouco tempo, por volta de um ano, mas comportaram-se com reciprocidade no desenvolvimento de sinais de confiança e comprometimento. $O$ sujeito 4 confiou em deixar o sujeito 3 tratar diretamente com o cliente (confiança), e o sujeito 3 comprometeu-se a não usufruir da oportunidade para resultados pessoais (comprometimento). Conforme os dois sujeitos relataram, mesmo que não se encontrem imediatamente para um novo trabalho, construíram uma base de relacionamento.

Pode-se inferir, portanto, que as atitudes e comportamentos dos atores, quando não seguem a macrocultura do negócio, podem criar condições de ações coletivas fundadas na confiança e cooperação. A macrocultura do negócio ficou clara nas quatro entrevistas, mostrando uma competição acirrada, oportunismo, variabilidade de formação de grupos de trabalho; mas os dois sujeitos trilharam outro caminho. Esta evidência é distinta da afirmativa de Jones e Lichtenstein (2007) sobre 
a macro cultura ocupar o espaço da lacuna da cultura criada no grupo. Esta sub-rede de dois atores fez o caminho contrário.

\section{Conclusão}

O trabalho investigou a formação e a dinâmica de redes temporárias a partir das afirmativas da perspectiva social de redes e das afirmativas da sociedade em rede. Para tanto, foram criados indicadores oriundos de trabalhos anteriores dos autores. O desenvolvimento e teste desses indicadores é um benefício metodológico do trabalho, já que são raros esses esforços na literatura brasileira.

Realizadas as entrevistas até o ponto de exaustão, a resposta convergente é que o grupo de organizações participantes de um evento apresenta fracos sinais de redes, eventualmente, alguns episódios de confiança e de comprometimento e algumas parcerias que se estendem para além do evento. Também de forma convergente, os sujeitos relataram que o negócio se caracteriza por uma acirrada competição, por papéis não claros entre os atores (por exemplo, a banda, que é um cliente, também pode ser agente de outro artista), por ausência de controle fiscal e por ciclos de vida curtos dos equipamentos. Os técnicos que operam os aparelhos, geralmente trabalhando para o cliente, têm um papel importante na indicação dos fornecedores e recebem comissões por isso.

O conjunto de dados permite concluir que as redes de eventos móveis são incipientes e que o curto período de aproximação e o trabalho conjunto das organizações são um entrave ao desenvolvimento e manutenção de laços sociais fortes. Por outro lado, eventos isolados de relações sociais mais fortes (como entre os sujeitos 3 e 4) indicam redes mais maduras, no sentido de menos conflito, mais confiança, menos incerteza em reagrupar os parceiros em eventos futuros e ações cooperadas de desenvolvimento do negócio, mesmo sem eventos programados. 
Dito de outra forma, há uma rede fracamente estabelecida durante o planejamento e execução do evento, mesmo diante de interdependência e necessidades de cooperação e troca de informações. Paralelamente, os discursos dos sujeitos mostraram que há uma rede mais perene em desenvolvimento, por exemplo, nas relações entre os sujeitos 2 e 3, ou entre os sujeitos 3 e 4 , que se refletem na equipe que se forma a cada evento. Nessa rede, que vai formando uma teia de fundo que permeia as ações comerciais e técnicas mais imediatas dos projetos, encontram-se sinais mais claros de confiança e comprometimento.

Sobre a governança, que aparece na sua natureza formal nos contratos de eventos, ela não se mostrou uma categoria básica na formação, ou dinâmica da rede, diferente do que afirmam, por exemplo, Grandori e Soda (1995). No modelo de Larson (1992), as relações sociais aparecem em um terceiro estágio de formação das redes, quando os papéis começam a se definir. Nos eventos móveis, os papéis já estão definidos por antemão, não havendo os estágios preconizados por Larson. Os eventos móveis, portanto, podem apresentar formas, processos e relações distintas das redes perenes.

A revisão bibliográfica indicou raridade de estudos sobre redes temporárias, mas existem muitos eventos com tempo marcado. Negócios como reforma de imóveis, projetos acadêmicos financiados com prazos determinados, projetos de campanhas políticas e visita de personalidades também apresentam o tempo limitado como seu eixo. Constituem, conforme entendem os autores, um campo de interesse, pois se consegue isolar a variável tempo com clareza tal que em outros negócios não é possível. Este artigo mostrou que o evento temporário pode gerar conhecimentos sobre as redes.

\section{Referências}

BERTRAND, Pauget. ANDREAS, Wald. Relational competence in complex temporary organizations: The case of a French hospital construction project network. International Journal of Project Management, v.31, n.2, p.200-211, February 2013. 
BEUGELSDIJK, Sjoerd. A note on the theory and measurement of trust in explaining differences in economic growth. Cambridge Journal of Economics, v.30, .1, p.371-387, Maio 2006.

BOEHE, Dirk.; BALESTRO, Moisés. A dimensão nacional dos custos de transação: oportunismo e confiança institucional. Revista Eletrônica de Administração-REAd, Porto Alegre/RS, v.12, n.1, p.1-20, jan-fev 2006.

CASTELLS, Manuel. A sociedade em rede. São Paulo: Paz e Terra, 1999.

CERVO, A. L.; BERVIAN, P. A.; SILVA, R. Metodologia científica. 6. ed. São Paulo: Pearson Prentice Hall, 2007.

GIGLIO, Ernesto; KWASNICKA, Eunice. O lugar do consumidor nos textos sobre rede. In: ENCONTRO ANPAD, ENANPAD, 29, 2005, Brasília. Anais... Brasília: ANPAD, 2005. p. 1-16.

GIGLIO, Ernesto; RIMOLI, Celso; SILVA, Ralph. Reflexões sobre os fatores relevantes no nascimento e crescimento de redes de negócios na agropecuária. Organizações Rurais \& Agroindustriais, v.10, n.2, p.279-292, Maio/Agosto 2008.

GRANDORI, Anna; SODA, Giuseppe. Inter-Firms Networks: Antecedents, Mechanisms and Forms. Organization Studies, v.16, n.2, p.183-214, Mar.1995.

GRANOVETTER, Mark. Economic Action and Social Structure: The Problem of Embeddedness. The American Journal of Sociology, v.91, n.3, p.481-510, Nov. 1985.

GRIFFITH, Garry; PIGGOTT, Nicholas. Asymmetry in beef, lamb and pork farm-retail price transmission in Australia. Agricultural Economics, v.10, n.1, p.307-316, Maio1994.

GULATI, Ranjay. Social structure and alliance formation patterns: a longitudinal analysis. Administrative Science Quarterly, v.40, n.4, p.619-652, Dez. 1995. 
HERNANDEZ, Jose; MAZZON, Jose. Trust development in e-commerce and store choice: model and initial test. In: ENCONTRO ANPAD, ENANPAD, 29, 2005. Brasília. Anais... Brasília: ANPAD, 2005. p. 1-16.

IACONO, Mario; ESPOSITO, Vincenza; BERNI, Alessia. Temporary project network and innovation: research on the Italian regional wine industry. International Journal of Managing Projects in Business, v.6, n.2, p.274-292, March, 2013.

JONES, Candace; HESTERLY, William; BORGATTI, Stephen. A general theory of network governance. The Academy of Management Review, v.22, n.4, p.911-945, Outubro 1997.

JONES, Candance; LICHTENSTEIN, Benyamin. Temporary Interorganizational Projects. IN CROPPER, S.; EBERS, M. The Oxford Handbook of inter-organizations relations. Oxford: Oxford Press, chapter 9, p.231-255, June, 2008.

LARSON, Andrea. Network dyads in entrepreneurial settings: A study of the governance of exchange relationships. Administrative Science Quarterly, v.37, n.1, p.76-105, Mar.1992.

LORANGE, Peter; ROOS, Johan. Analytical steps in the formation of strategic alliances. Journal of Organizational Change Management, v.4, n.1, p.60-72, January/February, 1991.

MAYNTZ, Renate. Modernization and the logic of interorganizational networks. Knowledge and Policy, v.6, n.1, p.3-16, March 1993.

NOHRIA, Nitin; ECLES, Robert (Ed.) Networks and Organizations: structure, form, and action. Boston: Harvard Business School Press, 1992.

POWELL, Walter. Hibrid organizational arrangements: New form or transition development? California Management Review, v.30, n.1, p.67-87, Fall-1987.

VERGARA, Sylvia Constant. Projetos e relatórios de pesquisa em administração. 10 ed. São Paulo: Atlas, 2009, 94p. 
VILLA, Agostino. Temporary network of enterprises: managing complexity by a multi-agent architecture. Journal of Engineering Manufacture, v.216, n.1, p.611-616, April, 2002.

Artigo recebido em: 08/10/2014 Aprovado em: 28/12/2014 